\title{
Mathematical modeling in biology: philosophy and pragmatics
}

\author{
Rasmus Grønfeldt Winther* \\ Philosophy Department, University of California, Santa Cruz, CA, USA \\ *Correspondence: rgw@ucsc.edu
}

\section{INTRODUCTION}

Philosophy can shed light on mathematical modeling and the juxtaposition of modeling and empirical data. This paper explores three philosophical traditions of the structure of scientific theory - Syntactic, Semantic, and Pragmatic - to show that each illuminates mathematical modeling. The Pragmatic View identifies four critical functions of mathematical modeling: (1) unification of both models and data, (2) model fitting to data, (3) mechanism identification accounting for observation, and (4) prediction of future observations. Such facets are here explored using a recent exchange between two groups of mathematical modelers in plant biology. Scientific debate can arise from different philosophies of modeling.

\section{PHILOSOPHY OF SCIENCE AND MODELS}

Three distinct philosophical perspectives on the nature and dynamics of scientific theory were sequentially developed in the twentieth century. Each was a critique of the previous perspective. Each illuminates scientific modeling.

\section{SYNTACTIC VIEW: THE LOGICAL STRUCTURE OF SCIENTIFIC THEORY}

The SYNTACTIC VIEW (advocated by the Vienna Circle "Logical Positivists") took issue with nineteenth century German idealism and argued that a scientific theory was actually a set of sentences expressed in a logical language $L$ (e.g., Carnap, 1928/2003; Woodger, 1937; Hempel, 1966). The language $L$ consisted of inference rules (e.g., modus ponens) and logical terms (e.g., $\exists, \neg$ ) as well as two types of vocabulary: theoretical (e.g., "proton," "protein," or "proletariat") and observational (e.g., "hard," "liquid," or "blue"). Sentences could be of two forms - either theoretical (i.e., containing only theoretical vocabulary, or mixed, i.e., correspondence rules), or observational (i.e., containing no theoretical vocabulary and acquiring meaning only from experimental observations).

\section{SEMANTIC VIEW: THE MATHEMATICAL STRUCTURE OF SCIENTIFIC THEORY}

In the late 1950s and early 1960s, some philosophers of science critiqued the SYNTACTIC VIEW and focused on the history and sociology of scientific practice (e.g., Thomas Kuhn, Paul Feyerabend, N.R. Hanson). Another group suggested that a philosophy of science should focus on mathematical models, rather than logical languages. Van Fraassen, an innovative advocate of this SEMANTIC VIEW remarked:

\begin{abstract}
to present a theory, we define the class of its models directly, without paying any attention to questions of axiomatizability, in any special language, however relevant or simple or logically interesting that might be. And if the theory as such, is to be identified with anything at all - if theories are to be reified - then a theory should be identified with its class of models. (Van Fraassen, 1989, p. 222)
\end{abstract}

Models were "always a mathematical structure” (Van Fraassen, 1970, p. 327; Van Fraassen, 2008, p. 381), and theory was a family of mathematical models. The SEMANTIC VIEW explored the mathematical structure of science, including the hierarchy of models from high theory to phenomenological models (Suppes, 2002) and the nature of confirmation and validation (i.e., the correct semantics) of theoretical models (e.g., Lloyd, 1994).

\section{PRAGMATIC VIEW: FUNCTIONS AND} ASSUMPTIONS IN SCIENTIFIC THEORY

The perspectives on syntactic structures and semantic relations offered by the SYNTACTIC AND SEMANTIC VIEWS are insufficient to describe scientific modeling because

(1) Practices, instruments, and experiments interweave with mathematical modeling (e.g., Hacking, 1983).

(2) There are a variety of modeling syntaxes - mathematics, diagrams, narratives, simulations, and programs, etc. (e.g., Morgan and Morrison, 1999).
(3) Models have implicit functions and assumptions (e.g., Wimsatt, 2007; Winther, Forthcoming).

The PRAGMATIC VIEW focuses on contextual factors, the agents, and use. For example, philosopher Leo Apostel wrote:

Let then $\mathrm{R}(\mathrm{S}, \mathrm{P}, \mathrm{M}, \mathrm{T})$ indicate the main variables of the modelling relationship. The subject $S$ takes, in view of the purpose $\mathrm{P}$, the entity $\mathrm{M}$ as a model for the prototype T. (Apostel, 1960, p. 128)

The PRAGMATIC VIEW includes syntax and semantics, and explores assumptions and functions of models.

\section{FOUR FUNCTIONS OF MATHEMATICAL MODELING}

The PRAGMATIC VIEW helps us focus on the functions of mathematical models, including (1) unification of both models and data, (2) model fitting to data, (3) mechanism identification accounting for observation, and (4) prediction of future observations.

\section{UNIFICATION}

Unification involves the integration and synthesis of disparate types of evidence and models. For instance, Darwin unified hybridization, developmental, paleontological, and biogeographical data under a single theory. In mathematical modeling, unification often entails embedding-a subsumption relation allowing for the unification of (i) various mathematical theories/ models and (ii) the data pertinent to those theories/models (Friedman, 1983; Van Fraassen, 1989).

\section{MODEL FITTING}

Model fitting employs statistical procedures such as regression analysis and hypothesis testing. Although fitting is essential for model verification, models can be over fitted to accommodate all of the data, a practice called "fudging" by Lipton (2005), which 
can be addressed by the Akaike Information Criterion (Hitchcock and Sober, 2004; see Winther, 2009).

\section{MECHANISM IDENTIFICATION}

Mechanism identification uses various strategies, including (i) analysis (i.e., decomposition into constituent parts and processes, given a theoretical perspective), (ii) causal surgery (Pearl, 2000), and (iii) mechanism transplantation (see Winther, Forthcoming). Mathematical models assist in these strategies, and hence in mechanism identification (Winther, 2011).

\section{PREDICTION}

The relevance of an observation or datum for the testing, confirmation, and choice of mathematical models and theories is significantly greater if it is a novel prediction (e.g., Popper, 1963; see Winther, 2009). In this sense, an excellent prediction is surprising, validating, and correct.

\section{A CASE STUDY}

The foregoing is illustrated with a debate between two camps of modelers, each focusing on different modeling functions. The possibility of collaboration rather than conflict is explored and advocated.

\section{THE MODELS}

Prusinkiewicz et al. (2007) present a simple model for the development of inflorescences, which postulates a single parameter - vegetativeness ( veg) - as the indicator of flowering. If a meristem has a high veg, it continues to grow vegetatively. If it has a low level, it flowers. The model stipulates that levels of veg decrease over time and that meristems have one of two internal states: $A$ or B. Meristems can be apical or lateral. In each, veg drops and induces flowering at two different times: $T_{\mathrm{A}}$ and $T_{\mathrm{B}}$. Since lateral branches do not usually produce flowers (p. 1453), the model assumes that meristems in $A$ revert to $B$. This "transience" model emulates flowering patterns that are related empirically to two Arabidopsis genes, TERMINAL FLOWER and LEAFY. It also mimics genetic experimental data.

Álvarez-Buylla et al. (2007) present an alternative "toy model" inspired by Turing's (1952) morphogenesis model, wherein an activator auto-catalyzes and induces an inhibitor that inhibits the activator and diffuses more rapidly (see Winther, 2011).
Álvarez-Buylla et al. (2007) show that two hypothetical proteins $A$ (activator) and $L$ (inhibitor) can produce the same growth and flowering patterns as the Prusinkiewicz et al. (2007) model.

\section{SPEAKING AT CROSS-PURPOSES}

Prusinkiewicz etal. (2007) and Álvarez-Buylla et al. (2007) capture the same system behavior, yet they disagree about the other party's legitimate modeling claims. Álvarez-Buylla et al. (2007) write "The unjustified reduction of a complex network... to a pair of interacting genes, leads to conclusions that might not be accurate" (p. 102), whereas Prusinkiewicz and Coen (2007) retort: "We do not deny the importance of further interactions, but we find it important to get a clear grasp of the key principles before incorporating too many genes” (p. 154). Thus, Álvarez-Buylla et al. (2007) and Prusinkiewicz and Coen (2007) adopt differing but complementary perspectives on modeling functions. Álvarez-Buylla et al. (2007) emphasize model fitting and prediction and are skeptical of unification and of how to identify mechanism, whereas Prusinkiewicz and Coen (2007) focus on unification. Indeed, a simple unifying model has significant virtues, even if it is difficult for it to fit diverse and complex empirical situations.

Now, Prusinkiewicz et al. (2007) allude to the importance of unification: "We propose that a relatively simple developmental mechanism - the transient model - underlies the restriction of inflorescence types to a small region of morphospace" (p. 1455). Note that the model is itself considered a mechanism, a reification with which Álvarez-Buylla et al. (2007) take issue. Moreover, Prusinkiewicz and Coen (2007) argue: "[Our] ... approach is to simplify the problem through various levels of abstraction, and focus on the underlying principles" (p. 155). Prusinkiewicz and Coen (2007) endorse a ceteris absentibus ("all other factors absent/abstracted away") heuristic to context, a reasonable and productive strategy when unification is the goal.

In contrast, Álvarez-Buylla et al. (2007) present a methodological critique of Prusinkiewicz et al. (2007), emphasizing biological complexity and model fitting: "The point we are trying to make is that there might be several alternative mechanisms, such as the transient and toy ones, that could reproduce similar sets of patterns.
Hence, the replication of patterns observed in nature does not guarantee that the mechanism that underlies it in the real world has been discovered or explained" (p. 101). Put differently, a model can mimic reality for the wrong reasons. Comparative analysis of distinct proposed mechanisms, including novel discriminating predictions is necessary.

\section{CONCLUSION}

The preceding illustrates that no model can fully satisfy all the functions and virtues of modeling. For instance, every model is limited in scope and identifies only some mechanisms. There are tradeoffs among functions (Wimsatt, 2007); for instance, (1) unification comes at the price of model fitting and prediction, and (2) model fitting and mechanism identification are not always aligned. Because of these trade-offs, different researchers make distinct claims about which functions are primary and forget that a theory is often a family of mathematical models, with each model maximizing only some functions.

Modelers should not become prisoners of their own abstractions (Levins and Lewontin, 1980, p. 67), and should seek integration among reasonable models (Mitchell, 2003; Winther, 2011). The philosophical perspective I have here called The Pragmatic View makes our modeling functions explicit.

\section{ACKNOWLEDGMENTS}

Mariana Benítez, Karl Niklas, Michael Titcomb, and Michael J. Wade provided comments. Support was provided by the Academic Senate Committee on Research, UC Santa Cruz, and the Biocomplexity Center, Niels Bohr Institute, University of Copenhagen.

\section{REFERENCES}

Álvarez-Buylla, E. R., Benítez, M., and Espinosa-Soto, C. (2007). Phenotypic evolution is restrained by complex developmental processes. HFSP J. 1, 99-103.

Apostel, L. (1960). Towards the formal study of models in the non-formal sciences. Synthese 12, 125-161.

Carnap, R. (1928/2003). The Logical Structure of the World (Der Logische Aufbau der Welt). Peru, IL: Open Court.

Friedman, M. (1983). Foundations of Space-Time Theories. Relativistic Physics and Philosophy of Science. Princeton: Princeton University Press.

Hacking, I. (1983). Representing and Intervening. Introductory Topics in the Philosophy of Natural Science. Cambridge: Cambridge University Press.

Hempel, C. G. (1966). Philosophy of Natural Science. Englewood Cliffs, NJ: Prentice-Hall. 
Hitchcock, C., and Sober, E. (2004). Prediction versus accommodation and the risk of overfitting. $\mathrm{Br}$. J. Philos. Sci. 55, 1-34.

Levins, R., and Lewontin, R. C. (1980). Dialectics and reductionism in ecology. Synthese 43, 47-78.

Lipton, P. (2005). Testing hypotheses: predictions and prejudice. Science 307, 219-221.

Lloyd, E. A. (1994). The Structure and Confirmation of Evolutionary Theory. Princeton: Princeton University Press.

Mitchell, S. (2003). Biological Complexity and Integrative Pluralism. Cambridge: Cambridge University Press.

Morgan, M.S., and Morrison, M. (eds.) (1999). Models as Mediators. Perspectives on Natural and Social Sciences. Cambridge: Cambridge University Press.

Pearl, J. (2000). The Art and Science of Cause and Effect. Available at: http://singapore.cs.ucla.edu/ LECTURE/lecture_sec1.htm [accessed April 12, 2011].

Popper, K. R. (1963). Conjectures and Refutations. The Growth of Scientific Knowledge. London: Routledge \& Kegan Paul.
Prusinkiewicz, P., and Coen, E. (2007). Passing the El Greco test. HFSP J. 1, 152-155.

Prusinkiewicz, P., Erasmus, Y., Lane, B., Harder, D., and Coen, E. (2007). Evolution and development of infloresence architectures. Science 316, 1452-1456.

Suppes, P. (2002). Representation and Invariance of Scientific Structures. Stanford, CA: CSLI Publications.

Turing, A. (1952). The chemical basis of morphogenesis. Philos. Trans. R. Soc. Lond. B Biol. Sci.237, 37-72.

Van Fraassen, B. (1970). On the extension of Beth's semantics of physical theories. Philos. Sci.37, 325-339.

Van Fraassen, B. (1989). Laws and Symmetry. New York: Oxford University Press.

Van Fraassen, B. (2008). Scientific Representation: Paradoxes of Perspective. New York: Oxford University Press.

Wimsatt, W. C. (2007). Re-Engineering Philosophy for Limited Beings: Piecewise Approximations to Reality. Cambridge: Harvard University Press.

Winther, R. G. (2009). Prediction in selectionist evolutionary theory. Philos. Sci. 76, 889-901.

Winther, R. G. (2011). Part-whole science. Synthese 178, 397-427.
Winther, R. G. (Forthcoming). "Evo-Devo as a trading zone" in Conceptual Change in Biology: Scientific and Philosophical Perspectives on Evolution and Development, Boston Studies in the Philosophy of Science, ed. A. Love (Springer Verlag).

Woodger, J. H. (1937). The Axiomatic Method in Biology. Cambridge: Cambridge University Press.

Received: 27 April 2012; accepted: 01 May 2012; published online: 07 June 2012.

Citation: Winther RG (2012) Mathematical modeling in biology: philosophy and pragmatics. Front. Plant Sci. 3:102. doi: $10.3389 / \mathrm{fpls.2012.00102}$

This article was submitted to Frontiers in Plant Evolution and Development, a specialty of Frontiers in Plant Science.

Copyright (c) 2012 Winther. This is an open-access article distributed under the terms of the Creative Commons Attribution Non Commercial License, which permits non-commercial use, distribution, and reproduction in other forums, provided the original authors and source are credited. 